\title{
Putative Biomarkers for Malignant Pleural Mesothelioma Suggested by Proteomic Analysis of Cell Secretome
}

\author{
SERENA LACERENZA ${ }^{1}$, FEDERICA CIREGIA $^{1,2}$, LAURA GIUSTI $^{3,4}$, ALESSANDRA BONOTTI $^{5}$, VIVIANA GRECO ${ }^{6,7}$, \\ GINO GIANNACCINI ${ }^{1}$, VANESSA D'ANTONGIOVANNI ${ }^{1}$, POUPAK FALLAHI ${ }^{5}$, LUISA PIERONI $^{8}$, \\ ALFONSO CRISTAUDO $^{5}$, ANTONIO LUCACCHINI ${ }^{4}$, MARIA ROSA MAZZONI ${ }^{1 *}$ and RUDY FODDIS ${ }^{5 *}$ \\ ${ }^{1}$ Department of Pharmacy, University of Pisa, Pisa, Italy; \\ ${ }^{2}$ Department of Rheumatology, GIGA Research, Centre Hospitalier Universitaire (CHU) de Liège, Liège, Belgium; \\ ${ }^{3}$ School of Pharmacy, University of Camerino, Camerino, Italy; \\ ${ }^{4}$ Department of Clinical and Experimental Medicine, University of Pisa, Pisa, Italy; \\ ${ }^{5}$ Department of Translational Research and New Medical and Surgical Technologies, \\ Occupational Medicine Unit, University-Hospital of Pisa, Pisa, Italy; \\ ${ }^{6}$ Institute of Biochemistry and Clinical Chemistry, Università Cattolica del Sacro Cuore, Rome, Italy; \\ ${ }^{7}$ Fondazione Policlinico Universitario A. Gemelli IRCCS, Rome, Italy; \\ ${ }^{8}$ Proteomics and Metabonomics Unit, IRCCS-Fondazione Santa Lucia, Rome, Italy
}

\begin{abstract}
Background: Malignant pleural mesothelioma $(M P M)$ a rare neoplasm linked to asbestos exposure is characterized by a poor prognosis. Soluble mesothelin is currently considered the most specific diagnostic biomarker. The aim of the study was to identify novel biomarkers by proteomic analysis of two MPM cell lines secretome. Materials and Methods: The protein patterns of MPM cells secretome were examined and compared to a non-malignant mesothelial cell line using two-dimensional gel electrophoresis coupled to mass spectrometry. Serum levels of candidate biomarkers were determined in MPM patients and control subjects. Results: Two up-regulated proteins involved in cancer biology, prosaposin and quiescin Q6 sulfhydryl oxidase 1 , were considered candidate biomarkers. Serum levels of both proteins were significantly higher in MPM patients than control subjects. Combining the data of each receiveroperating characteristic analysis predicted a good diagnostic accuracy. Conclusion: A panel of the putative biomarkers represents a promising tool for MPM diagnosis.
\end{abstract}

This article is freely accessible online.

*These Authors contributed equally to this study.

Correspondence to: Professor Maria Rosa Mazzoni, Department of Pharmacy, University of Pisa, Via Bonanno 6, 56126 Pisa, Italy. Tel: +390502219524, e-mail: maria.mazzoni@unipi.it

Key Words: Malignant pleural mesothelioma, biomarkers, proteomic analysis, secretome, proteome, cell lines.
Malignant mesothelioma is a highly aggressive cancer, that can affect any kind of serosal membrane. In particular, malignant pleural mesothelioma (MPM) represents less than $1 \%$ of known cancers but its incidence will continue to increase significantly at least until 2030. Despite a complex etiology, the predominant factor causing MPM is the inhalation of asbestos fibers. Widespread employment of asbestos in the last century, combined with the high biopersistence of asbestos fibers, accounts for the extraordinary proportion of people exposed to asbestos for occupational or environmental reasons. Latency time for MPM shows a great variability, but a latency period shorter than 10 years is very rare. Early diagnosis and differential diagnosis are very difficult and thus most patients are diagnosed with advancedstage disease and have median survival time less than 12 months (1). Nowadays, the main instruments for screening and early diagnosis are still based on radiological tests with evident ethical and economical problems (2). Over the years, numerous candidate biomarkers have been proposed with significance of screening, early diagnostic and prognostic markers. A combination of two positive (mesothelial) and two negative (cancer-related) markers is considered the gold standard for immunohistochemical diagnosis of epitheliod and biphasic MPM while the rare sarcomatoid type has no specific markers (3). Among biomarkers in body fluids such as serum, plasma and pleural effusion (PE), soluble mesothelin-related peptide (SMRP), also known as mesothelin, is the best characterized and well known displaying high specificity for MPM, but a low sensitivity (3-6). Therefore, levels of SMRP in the body fluids cannot be considered as the sole modality of diagnostic marker (3). 
Osteopontin has been reported as a promising biomarker to discriminate early-stage MPM patients among an asbestosexposed population but its usefulness in screening is compromised by the low specificity (3). Fibulin-3 has been also indicated as a promising biomarker with high specificity and selectivity for MPM (7). However, later studies carried out on both plasma and PE did not confirm the diagnostic potency of fibulin-3 $(8,9)$. On the other hand, fibulin-3 has been suggested as a prognostic biomarker while SMRP levels in both plasma and PE do not seem to possess any prognostic value $(8,10)$. During the last years, a number of studies have identified differential microRNA expression in malignant mesothelioma cell lines (3). Thereafter, a pool of deregulated circulating and tissue miRNAs with biomarker potential for MPM has been identified $(4,11)$. Nevertheless, there is still the need of novel biomarker identification which can be of use to screen asbestos-exposed subjects, detect early-stage MPM patients, and provide a prognostic prediction.

Recently, some investigations have examined the overall protein expression landscape of MPM cell lines in order to gain insight in the molecular characteristics of the disease, possibly identifying molecules that might be useful biomarkers and also discover novel therapeutic targets. In particular, these studies focused on analyzing the whole secreted proteins by MPM cell lines using a proteomics approach (12-14). Indeed, the whole proteins secreted by cells, known as "secretome", offer valuable information on malignant cell communications and molecular mechanisms of their spreading.

In order to obtain an inclusive overview of MPM cell protein expression we examined the proteome and secretome profiles of two MPM cell lines, NCI-H28 and NCI-2052 cells, and compared them to the profiles of a non-malignant mesothelial cell line (Met-5A). Through this proteomic approach, two differentially expressed secreted proteins related to cancer biology were identified and were subsequently validated in serum of asbestos-exposed healthy subjects and MPM patients by enzyme-linked immunosorbent assay (ELISA). The validation phase highlighted both secreted proteins were present at significantly higher levels in sera of MPM patients than control subjects. The information gained from this study increased our knowledge on MPM biology and identified two novel potential biomarkers. Further investigations on a larger number of serum samples are required to confirm the predictive value of these novel biomarkers.

\section{Materials and Methods}

Materials. Iodoacetamide, dithiothreitol (DTT), 3-((3cholamidopropyl) dimethylammonio)-1 propanesulfonate (CHAPS), urea, thiourea, glycerol, sodium dodecyl sulfate (SDS), tetramethylethylenediamine (TEMED), ammonium persulfate (APS), glycine and $30 \%$ acrylamide- $\mathrm{N}, \mathrm{N}, \mathrm{N}$ bisacrylamide were from Applichem
(Darmstadt, Germany). IPGs pH 3-10 NL, IPG-buffer 3-10 NL and dry stripcover fluid were purchased from GE Health Care Europe (Uppsala, Sweden). Ruthenium II tris (bathophenantroline disulfonate) tetrasodium salt (RuBP) stain was obtained from Cyanagen Srl (Bologna, Italy). Medium 199, RPMI-1640, fetal bovine serum (FBS), trypsin-EDTA, epidermal growth factor (EGF), and human recombinant insulin were purchased from Life Technologies Corporation (Carlsbad, CA, USA). Prosaposin (PSAP) and Quiescin Q6 Sulfhydryl Oxidase 1 (QSOX1) ELISA kits were obtained from Cloud-Clone Corp. (Katy, TX, USA). All other reagents were from standard commercial sources and were of the highest grade available.

Patients. Serum samples from MPM patients and asbestos-exposed healthy subjects (control subjects) (Table I) were obtained prospectively at the Occupational Medicine Unit of the UniversityHospital of Pisa from 2008 to 2016. Sera were available from 36 subjects previously exposed to asbestos, not affected by MPM or any other neoplasm, which were examined at the University Hospital of Pisa in years 2008-2013 within a follow-up program of health surveillance established by the Occupational Medicine Unit. Thirty-two MPM patients were enrolled at the time of diagnosis, before beginning any therapeutic treatment. All MPM were epithelioid types by histology. Each serum sample was coded at the moment of collection, in order to avoid any personal identification; all data were treated in accordance with the Italian law of privacy (number 675/96) and handled as approved by the Local Ethical Board and in accordance with the Helsinki declaration. For all patients and control subjects, age, sex, smoking habit, years of work, and asbestos exposure are indicated in Table I.

Ethics statements. The research was carried out according to The Code of Ethics of the World Medical Association (Declaration of Helsinki), and the author's institutional review board had previously approved the study, which was also approved by the Local Ethics Committee (Comitato per la Sperimentazione Clinica dei Farmaci, Azienda Ospedaliera Universitaria Pisana) and signed consent forms were obtained from all patients.

Cell culture and protein sample preparation. All cell lines mentioned here were obtained from ATCC (Manassas, VI, USA). A non-malignant mesothelial cell line (Met-5A, ATCC ${ }^{\circledR}$ CRL-9444 ${ }^{\mathrm{TM}}$ ) and two MPM cell lines, NCI-H28 (ATCC ${ }^{\circledR}$ CRL-5820 ${ }^{\mathrm{TM}}$ ) and NCIH2052 (ATCC ${ }^{\circledR}$ CRL-5915 ${ }^{\mathrm{TM}}$ ) were used in this study. Both MPM cell lines were grown in RPMI-1640 medium supplemented with $10 \% \mathrm{FBS}$ and $1 \%$ penicillin/streptomycin $(100 \mathrm{U} / \mathrm{ml} / 100 \mu \mathrm{g} / \mathrm{ml})$ as described $(15,16)$. Met-5A cells were grown in Medium 199 supplemented with $10 \% \mathrm{FBS}, 1 \%$ penicillin/streptomycin (100 units $/ \mathrm{ml} / 100 \mu \mathrm{g} / \mathrm{ml})$, hydrocortisone (400 nM), EGF (3.3 nM) and human recombinant insulin $(870 \mathrm{nM})$ as previously described (15). Met-5A were normally propagated in their own growth medium except for preparation of whole cell lysate (WCL) and conditioned medium $(\mathrm{CM})$.

To investigate both proteome and secretome profiles, cells were grown at $80 \%$ confluence in complete culture media. Then, the cell monolayer was gently rinsed three times with phosphate buffer saline (PBS) and once with RPMI-1640 medium without serum and then incubated for $24 \mathrm{~h}$ in serum-free medium. In order to determine the optimal rinsing conditions and incubation time, cell viability was evaluated by the trypan blue assay dye exclusion. 
Table I. Patient and control subject features.

\begin{tabular}{lcc}
\hline & Exposed $^{\mathrm{a}}$ & MPM $^{\mathrm{b}}$ \\
\hline $\mathrm{N}$ & 36 & 32 \\
Age (mean \pm SD) & $60 \pm 8$ & $67 \pm 8$ \\
Gender $(\%)$ & & \\
$\quad$ Male & 89 & 78 \\
$\quad$ Female & 11 & 22 \\
Smoking habit $(\%)$ & 14 & \\
$\quad$ Smokers & 50 & 14 \\
$\quad$ Non-smokers & 36 & 34 \\
$\quad$ Ex-smokers & $33 \pm 8$ & $32 \pm 11$ \\
Years of work (mean \pm SD) & 100 & 93 \\
Asbestos exposure $(\%)$ & & \\
\hline
\end{tabular}

aExposed: Asbestos-exposed healthy subjects (control subjects). bMPM: MPM patients.

$\mathrm{CM}$ was collected and centrifuged at 1,100 rpm for $5 \mathrm{~min}$ to eliminate detached cells and large debris. The supernatant was concentrated by ultrafiltration using a $0.45 \mu \mathrm{M}$ membrane (Merck Millipore, Burlington, MA, USA). The concentrated sample was subjected to $20 \%$ trichloroacetic acid (TCA) precipitation at $4^{\circ} \mathrm{C}$. Precipitated proteins were resuspended in rehydration buffer $(7 \mathrm{M}$ urea, $2 \mathrm{M}$ thiourea, $4 \%$ CHAPS, and $0.002 \%$ bromophenol blue) containing $60 \mathrm{mM}$ DTT and the protein content was measured by the RC/DC assay (Bio-Rad, Hercules, CA, USA). Bovine serum albumin (BSA) was used as a standard. The remaining cell monolayer was gently rinsed three times with PBS and then the dish was frozen at $-80^{\circ} \mathrm{C}$. At the time of use, cells were lysed by scraping in rehydration buffer containing $60 \mathrm{mM}$ DTT and the protein content of WCL was determined by the RC/DC assay (BioRad, Hercules, CA, USA). The parallel proteomic profiling of WCL was used as a background to filter out intracellular contaminants and enrich for secreted proteins. A schematic workflow of the protocol to prepare WCL and CM samples is outlined in Figure 1. For each cell line, the experimental procedure described above was repeated four times.

Two-dimensional electrophoresis. Two-dimensional electrophoresis (2-DE) was performed as previously described (17). Briefly, $200 \mu \mathrm{g}$ of proteins were filled up to $450 \mu \mathrm{l}$ in rehydration buffer supplemented with $1.2 \%$ (v/v) IPG-buffer, pH 3-10 NL (GE Health Care Life Sciences, Little Chalfont, UK). Isoelectric focusing (ISF) was carried out using $18 \mathrm{~cm}$ Immobiline Dry-Strips (GE Health Care Life Sciences, Little Chalfont, UK), pH 3-10 gradient, which were rehydrated overnight in the sample. The first dimension was performed at $16^{\circ} \mathrm{C}$ on an Ettan IPGphor II apparatus (GE Health Care Life Sciences, Little Chalfont, UK) according to the previously described procedure (18). Then, immobiline strips were equilibrated as previously described, and the second dimension (SDS-PAGE) was carried out by transferring proteins to $12.5 \%$ polyacrylamide gels, which were run overnight at $16 \mathrm{~mA}$ per gel, $10^{\circ} \mathrm{C}$, using the PROTEAN-II Multi Cell system (Bio-Rad, Hercules, CA, USA) (19). Gels were run in duplicate.

Staining and image analysis. Gels were stained with RuBP (Cyanagen Srl, Bologna, Italy) essentially as described (20). Briefly,
$\mathrm{H} 28$

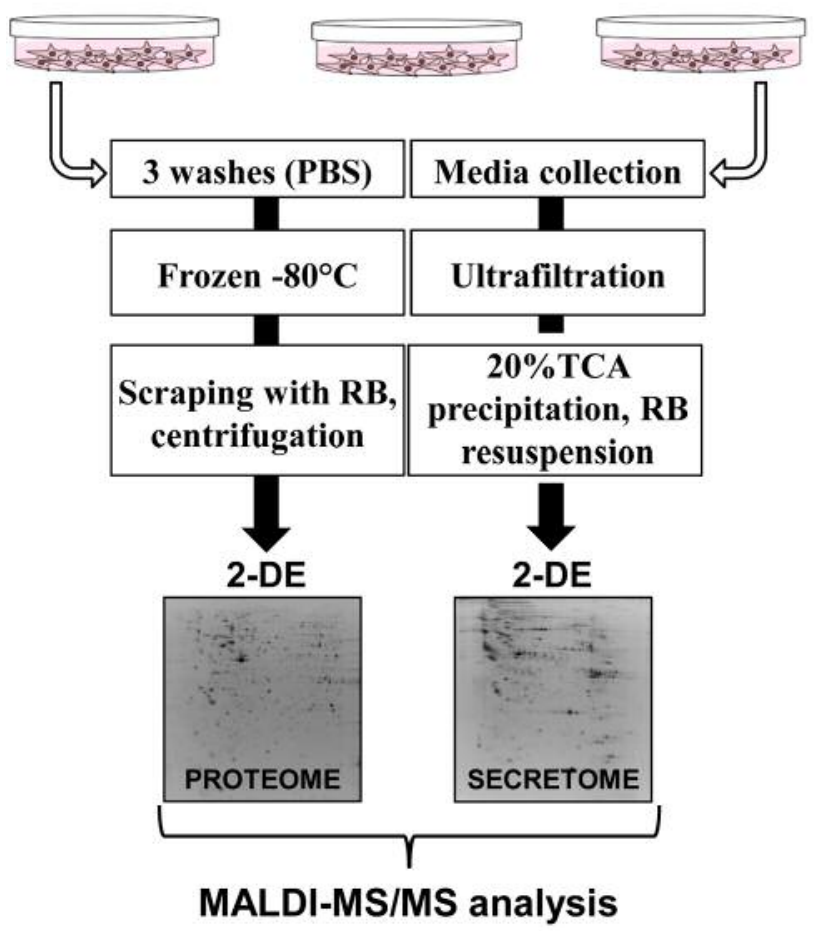

Figure 1. Schematic workflow of sample preparation for proteomic analysis. MPM (NCI-H28 and NCI-H2052) and mesothelial (Met-5A) cells were cultured as described in the Materials and Methods. CM containing secreted proteins was collected, concentrated, precipitated with TCA and resuspended in rehydration buffer $(R B)$. Each cell monolayer was rinsed three times with $P B S$ and the disc was frozen at $-80^{\circ} \mathrm{C}$. At the time of use, cells were lysed by scraping in $R B$ and debris removed by centrifugation in a microfuge at $14,000 \times \mathrm{g}$ for $10 \mathrm{~min}$. CM and WCL proteins were fractionated by 2-DE. Differentially expressed protein spots were cut out, trypsinized and analysed by MALDI-MS/MS. Each experiment was repeated four times.

after electrophoresis, gels were fixed in $1 \%(\mathrm{v} / \mathrm{v})$ phosphoric acid and $30 \%$ ethanol for $1 \mathrm{~h}$ at room temperature, then stained overnight with $1 \mu \mathrm{M}$ ruthenium complex in $1 \%$ phosphoric acid and $30 \%$ ethanol. Afterward, gels were destained for $4-6 \mathrm{~h}$ in $1 \%$ phosphoric acid and 30\% ethanol and rinsed in water prior to acquisition of fluorescence by ImageQuant LAS4010 (GE Health Care Life Sciences, Little Chalfont, UK). The images were analyzed using the Same Spot v4.1 software (TotalLab Ltd; Newcastle Upon Tyne, UK). Gel quality was assessed using the Spot-Check function. The spot volume ratios between MPM and Met-5A WCLs or CMs were calculated using the average spot normalized volume of four experimental replicate. The significance of the differences of normalized volume for each spot was calculated by the software Same Spot including the statistical analysis by ANOVA test. Protein spots with $\geq 2$ fold-change, $p<0.05$ and $q$-value $<0.05$ could be chosen for identification by MALDI-MS/MS.

Mass spectrometry (MS) analysis and protein identification. Spots of interest were cut out from gels, trypsinized as reported by Giusti et al. (21). Protein identification was performed according to Soggiu et al. (22). Briefly after the digestion protocol, peptides were 
desalted, concentrated by C18 ZipTip (Millipore) and cocrystallized with a solution of $0.5 \mathrm{mg} / \mathrm{ml} \quad \alpha$-ciano-4hydroxycinnamic acid (HCCA) (dissolved in 50\% acetonitrile, $0.05 \%$ trifluoroacetic acid (TFA)) on a Ground Steel plate (BrukerDaltonics, Bremen, Germany) previously spotted with a thin layer of $10 \mathrm{mg} / \mathrm{ml} \mathrm{HCCA}$ dissolved in ethanol/acetonitrile $/ 0.1 \%(\mathrm{v} / \mathrm{v})$ TFA in $\mathrm{H}_{2} \mathrm{O}$. MS data were acquired by Ultraflex III MALDITOF/TOF spectrometer (Bruker Daltonics) in positive reflectron mode. External calibration was performed using the standard peptide mixture calibration (m/z: 1046.5418, 1296.6848, 1347.7354, 1619.8223, 2093.0862, 2465.1983, 3147.4710; Bruker-Daltonics). FlexAnalysis 3.3 software (Bruker-Daltonics) was used for the selection of the monoisotopic peptide masses of each mass spectra. Internal calibration was performed on autolysis trypsin peaks $(\mathrm{m} / \mathrm{z}$ : 842.509 and 2211.104). After exclusion of contaminant ions (known matrix and human keratin peaks), the created peak lists were analyzed by MASCOT v.2.4.1 algorithm (www.matrixscience.com) against SwissProt 201907 database restricted to Homo Sapiens taxonomy (20352 sequences). Peptide Mass Fingerprinting (PMF) analysis was performed with the following parameters: carbamidomethylation of cysteines as fixed modification, oxidation of methionines as variable modification, one missed cleavage site allowed for trypsin and $50 \mathrm{ppm}$ as maximal tolerance. Mascot protein scores greater than 52 were considered significant $(p<0.05)$ for protein identification assignment. To confirm the protein identification obtained from PMF analysis, the instrument was switched to LIFT mode. MS/MS spectra were acquired, precursor ions manually selected and the precursor mass window was automatically set (23). MS/MS spectra analyses were carried out by Flex Analysis 3.3 software according to the following steps: spectra baseline subtraction, smoothing Savitsky-Golay and centroiding. For database search, the following parameters used were set as: carbamidomethylation of cysteines and oxidation of methionine for fixed and variable modifications respectively, one missed cleavage, $50 \mathrm{ppm}$ for the mass tolerance for precursor ions and 0.4 Da for fragments. The taxonomy was restricted to Homo sapiens. The confidence interval for protein identification was set to $95 \%$ $(p<0.05)$; peptides with individual ions scores higher than 32 , which indicate identity or extensive homology, were considered.

Validation analysis in serum samples. Serum levels of candidate biomarkers, PSAP and QSOX1, were measured using commercially available sandwich-type ELISA kits (Cloud-Clone Corp., Katy, USA) according to manufacturer's instructions. Briefly, serum samples were diluted 1:50 (PSAP) or 1:5 (QSOX1) using $10 \mathrm{mM}$ PBS, $\mathrm{pH}$ 7.1. Blanks, diluted standards and samples $(100 \mu \mathrm{l})$ were added to 96-well strip plates pre-coated with an anti-PSAP or QSOX1 specific antibody and incubated for $1 \mathrm{~h}$ at $37^{\circ} \mathrm{C}$. Then, wells were washed, an anti-PSAP or -QSOX1 biotin-conjugated specific antibody added, and incubated for $1 \mathrm{~h}$ at $37^{\circ} \mathrm{C}$. The plates were washed again, the avidin conjugated horseradish peroxidase (HRP) added, and incubated for $30 \mathrm{~min}$ at $37^{\circ} \mathrm{C}$. Then, the plates were washed, the (3,3', 5,5;-tetramethylbenzidine) chromogen solution (TMB) added and incubated for $10 \mathrm{~min}$ at $37^{\circ} \mathrm{C}$ in the dark. The enzyme-substrate reaction was quenched by the addition of a sulfuric acid solution and the color change was measured spectrophotometrically at a wavelength of $450 \mathrm{~nm}$. PSAP and QSOX1 sample concentrations $(\mathrm{ng} / \mathrm{ml})$ were determined by comparing the optical density (OD) of the samples to PSAP and QSOX1 standard curves, respectively.
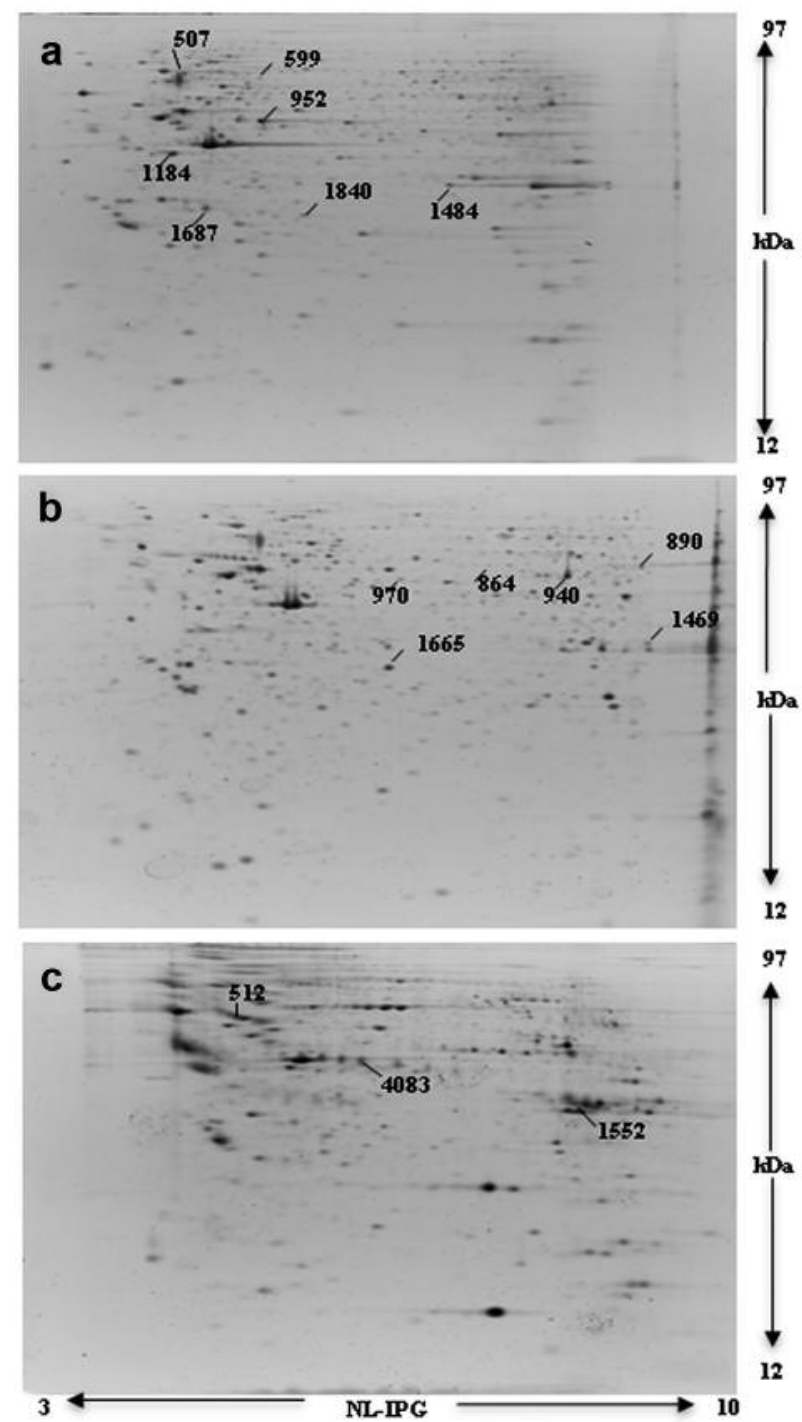

Figure 2. Representative 2-DE gel images of MPM cell proteome and secretome. WCL and CM proteins were fractionated by 2-DE as described in the Materials and Methods. Proteins were detected by RuBP staining. Spots, that showed the highest fold increase in MPM cell samples compared to Met-5A cell WCL and CM, are pointed. These spots were excised, trypsinized and analysed by MALDI-MS/MS for protein identification.

Statistical analysis of ELISA data. Measurements of biomarker serum levels were performed in duplicate and repeated at least three times for each sample. Results were analyzed by Shapiro-Wilk test to define the potential Gaussian distribution in order to choose the appropriate statistical method. Since variables were not normally distributed, differences between groups were analyzed by MannWhitney-Wilcoxon test. Data analysis was performed using an open source software ( $\mathrm{R}$ v3.5.2).

Receiver-operating characteristic (ROC) curves were plotted using standard techniques to assess sensitivity and specificity of serum PSAP and QSOX1 to differentiate MPM patients from asbestos-exposed healthy subjects. Areas under curves (AUC) were 
calculated with their $95 \%$ confidence intervals $(95 \% \mathrm{CI})$. In order to estimate whether biomarker combination could increase their performance in differentiating MPM patients from asbestos-exposed healthy controls, the data from the two biomarkers were combined using a logistic regression analysis. Statistical analysis was performed using IBM SPSS v20.0 (SPSS Inc, Chicago, IL, USA).

\section{Results}

Proteomic analysis of WCL and CM. In order to characterize WCL and CM protein profiles, NCI-H2052, NCI-H28 and Met-5A cells were grown for $24 \mathrm{~h}$ in serum-free RPMI-1640 medium, then CMs were collected and cells harvested as described in Materials and Methods. In preliminary experiments, the trypan blue dye exclusion assay demonstrated that after $24 \mathrm{~h}$ of serum starvation Met-5A, NCI-H2052, and NCI-H28 cells remained $91.93 \pm 1.00 \%$ $($ mean \pm SEM; $n=3), 98.43 \pm 1.50 \%($ mean \pm SEM; $n=3)$, and $94.73 \pm 2.35 \%($ mean \pm SEM; $n=3)$ viable, respectively.

After WCL and CM protein fractionation by 2-DE and gel staining, a comparative analysis between MPM and Met-5A cells was performed. As mentioned in Materials and Methods, normalized spot volumes were analyzed by the ANOVA test to detect the proteins, which were significantly different for each comparison $(p<0.05)$. We found 1107 protein spots by NCI-H2052 versus Met-5A WCL analysis. Twenty spots out of 342 , which showed significant expression variations, were increased and 13 decreased in NCI-H2052 proteome with fold changes greater than 2. NCIH28 versus Met-5A WCL analysis also highlighted 1107 protein spots of which 270 were differentially expressed in a significant manner. Among them, 9 spots displayed an increased expression in NCI-H28 proteome while 9 showed a reduction with fold changes greater than 2 .

A comparison between NCI-H2052 and Met-5A CMs showed 91 differentially expressed protein spots. Among them, 7 were increased in NCI-H2052 secretome while 10 were decreased with fold changes major than 2 . We were unable to perform NCI-H28 secretome analysis since low protein amounts were repeatedly recovered in the resuspended TCA precipitate of the ultrafiltrated CM. Figure 2 shows representative 2-DE gel images of MPM cell line proteome and secretome.

Among the most abundant and differentially expressed proteins in WCL and CM of MPM cell lines compared to Met-5A cells, spots with the highest fold increase were selected, excised and trypsin-digested. A graphical representation of each spot volume and enlarged images of the selected spots are shown in Figure 3. Tryptic peptides of excised spots were analyzed by MALDI-MS/MS. Identified proteins are summarized in Table II. Among the three identified proteins in the NCI-H2052 cell secretome, PSAP and QSOX1 gained our attention since they are involved in protecting cells against oxidative stress that is a main driver of malignant transformation including MPM development (24-27). These proteins which have been also detected upregulated in the secretome of other MPM cell lines (14) can play a protective role against endogenous and exogenous reactive oxygen species (ROS) thus contributing to cancer cell escape from apoptosis.

Validation of proteomic data in serum samples. The prospective role as novel tumor-derived biomarkers of two proteins, PSAP and QSOX1, significantly increased with the highest fold variation in NCI-H2052 cell secretome compared to that of Met-5A cells was evaluated. PSAP and QSOX1 were validated on serum samples of asbestosexposed healthy subjects and patients affected by MPM using commercially available ELISA kits. Thirty-two MPM patients and 36 control subjects were included in the study. Demographic, smoking habit, and working history of both groups under investigation are summarized in Table I.

Both PSAP and QSOX1 serum levels were significantly higher in MPM patients than in asbestos-exposed healthy subjects with $p<0.001$. Box plots of PSAP and QSOX1 serum concentrations are shown in Figures 4 and 5, respectively. Table III summarizes the ELISA results. Since PSAP and QSOX concentration values were not normally distributed, data in Table III are presented as median, $25^{\circ}$ percentile, and $75^{\circ}$ percentile.

The diagnostic power of these putative biomarkers was validated by the ROC curve. The AUC value was calculated for each protein individually to determine whether each biomarker alone can discriminate MPM patients from asbestos-exposed healthy subjects (Figure 6). The AUC for PSAP was 0.75 with $67 \%$ specificity and $75 \%$ sensitivity while the AUC for QSOX1 was 0.85 with $86 \%$ specificity and $84 \%$ sensitivity. Thus, serum QSOX1 turned out to have a higher diagnostic value than PSAP for distinguishing MPM patients from asbestos-exposed healthy subjects. Then we investigated whether the discriminative power of each biomarker could be increased by their combination. As a result, we found that the discriminative power increased if PSAP and QSOX1 were merged (Figure 6). Indeed, the AUC increased to 0.95 while specificity and sensitivity were $92 \%$ and $88 \%$, respectively.

\section{Discussion}

The present study was undertaken to identify differentially expressed proteins in two certified MPM cell lines compared to a normal mesothelial cell line (Met-5A) with the specific aim of discovering novel potential biomarkers for MPM diagnosis. Nowadays, the first-line diagnostic tool for this deadly cancer is mainly based on chest radiography followed by computerized tomography (CT) while serological biomarkers currently available seem to have some, but 

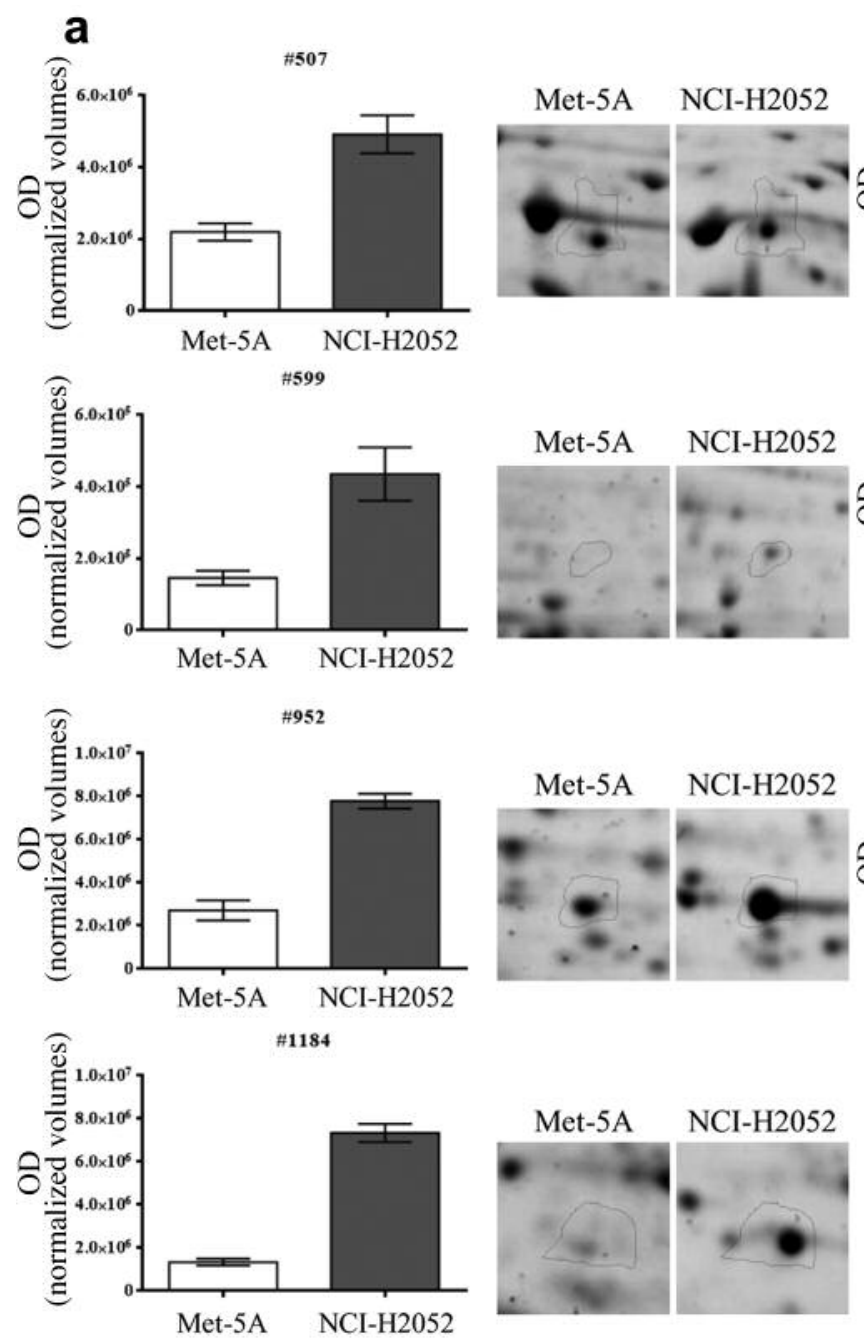
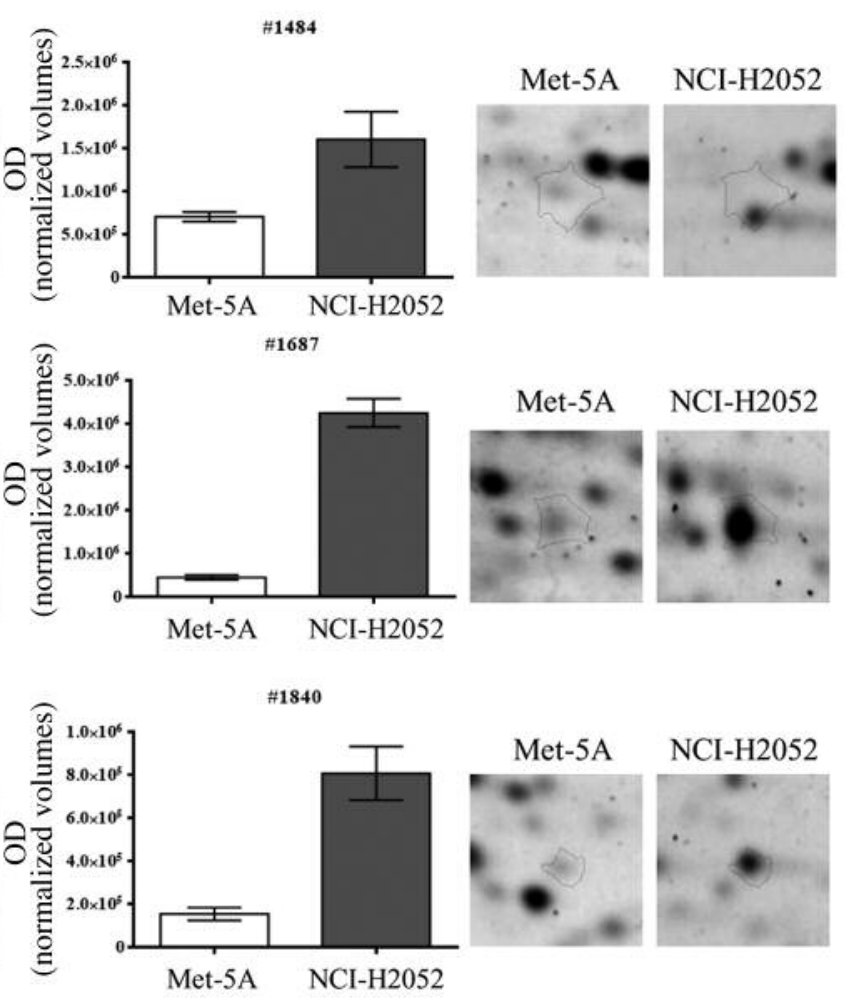

Figure 3. Continued limited use in screening asbestos-exposed subjects, disease diagnosis and monitoring (28). Indeed, no single biomarker has shown sufficient reproducibility and sensitivity to be of use by itself but promising results have been obtained using biomarker panels $(28,29)$. In recent years at least two studies, which have analyzed MPM cell secretome using a proteomic approach, have found numerous differentially expressed proteins related to various cellular pathways with significance in cancer biology $(13,14)$. Nevertheless, none of the identified proteins has been validated and tested as potential MPM biomarkers in patient and control subject body fluids. Here, we report a proteomic analysis of the NCI-H2052 cell line secretome with the identification of three differentially expressed proteins by MALDI-MS/MS. These proteins, which were reproducibly overexpressed in NCI-H2052 cell secretome compared to that of Met-5A cells, were selected among other protein spots in 2-DE gels on the basis of the highest fold-increase.
The most highly up-regulated protein in MPM cell secretome was PSAP. PSAP is the precursor protein of four lysosomal activator proteins known as the saposins A-D, which facilitate sphingolipid hydrolysis via lysosomal hydrolases while the full-length protein is released as a secreted factor (30). As secreted protein, PSAP is a neurotrophic factor capable of promoting cell survival, neurite out growth, protection against oxidative stress and differentiation of a cholinergic cell line (24, 31). Overexpression of both intracellular and secreted PSAP has been reported in prostate cancer cells where it promotes growth, migration and invasion as well as up-regulates androgen receptor and prostate specific antigen expression and activity (32-34). However, the role of PSAP in stimulating metastasis seems to be controversial since $\mathrm{Hu}$ et al. (35) reported a pro-metastatic effect while Kang et al. (36) suggested that suppression of PSAP expression in prostate and breast cancer cells may enhance their metastatic 

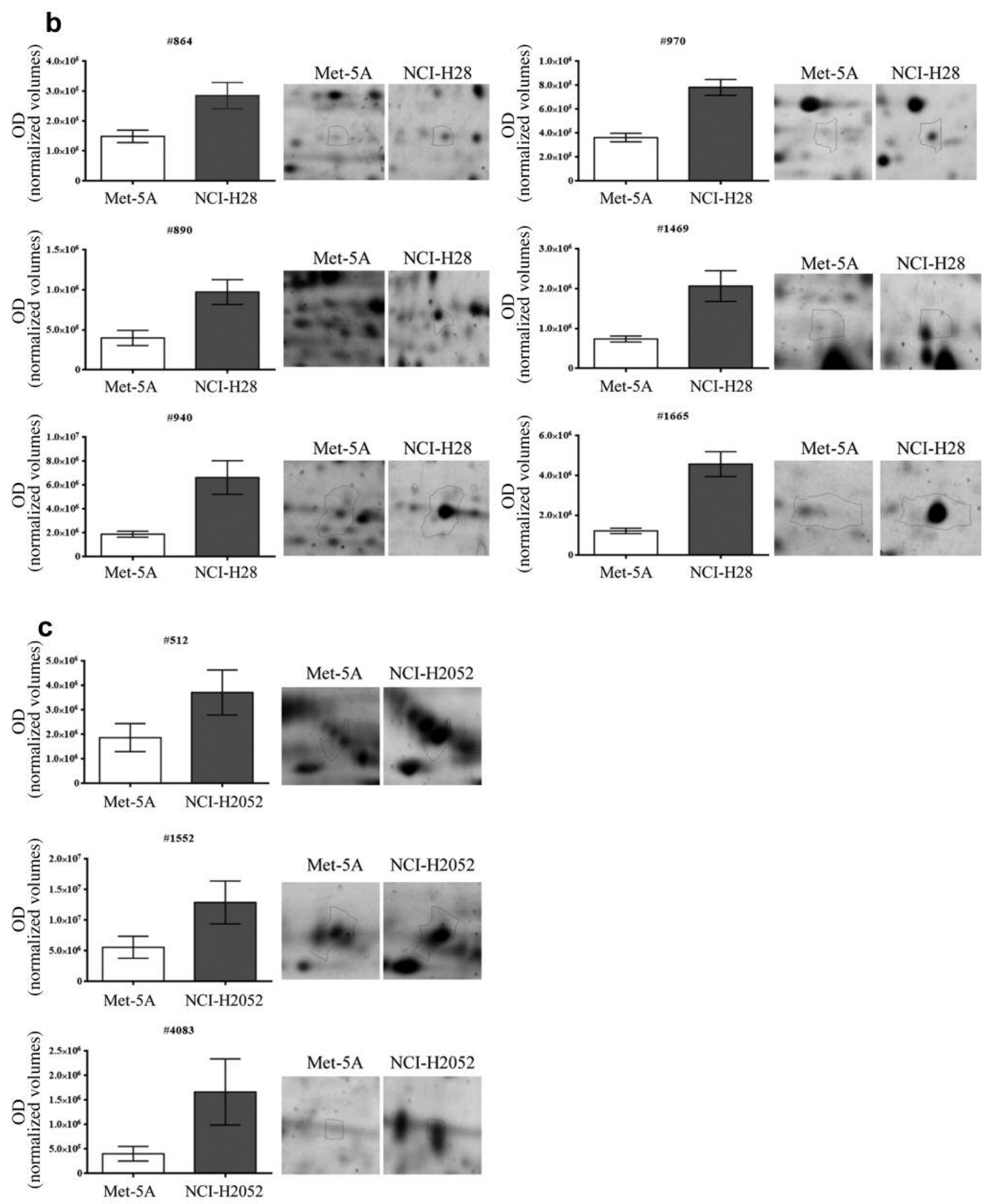

Figure 3. Histograms of selected spots differentially expressed. Data are presented as mean \pm SEM $(n=4)$ of the normalized spot volumes $(\%)$ in MPM cell samples compared to Met-5A cells. Spot number and corresponding identified protein are listed in Table II. Enlarged images of each spot are depicted beside the histograms. 
Table II. List of proteins identified by MALDI-MS/MS.

\begin{tabular}{|c|c|c|c|c|c|c|c|c|c|c|}
\hline Spot ID & $\begin{array}{l}\text { Protein } \\
\text { name }\end{array}$ & $\begin{array}{l}\text { Protein } \\
\text { ID }^{\mathrm{a}}\end{array}$ & Gene & $\mathrm{pI}^{\mathrm{b}}$ & $\begin{array}{c}\text { Mascot } \\
\text { score }^{c}\end{array}$ & $\begin{array}{l}\text { Cov } \\
(\%)^{\mathrm{d}}\end{array}$ & Pept ${ }^{\mathrm{e}}$ & $\begin{array}{l}\text { Mass } \\
(\mathrm{kDa})\end{array}$ & $p$-Value & Ratio $^{\mathrm{f}}$ \\
\hline \multicolumn{11}{|c|}{ NCI-H2052 cell proteome } \\
\hline 507 & Elongation factor 2 & P13639 & EEF2 & 6.4 & 84 & 28 & $6 / 55$ & 95 & 0.00279 & 2.2 \\
\hline 599 & NAD-dependent protein deacetylase sirtuin-1 & Q96EB6 & SIRT1 & 4.5 & 120 & 54 & $12 / 52$ & 82 & 0.00334 & 3.0 \\
\hline 952 & Cytochrome P450 1B1 & Q16678 & CYP1B1 & 9.2 & 78 & 46 & $16 / 52$ & 61 & 0.0007 & 2.9 \\
\hline 1184 & $\begin{array}{l}\text { Transforming growth factor beta-1-induced } \\
\text { transcript } 1 \text { protein }\end{array}$ & O43294 & TGFB1I1 & 6.6 & 64 & 32 & $8 / 32$ & 50 & 0.00002 & 5.5 \\
\hline 1484 & L-lactate dehydrogenase A chain & P00338 & LDHA & 8.4 & 142 & 60 & $11 / 31$ & 37 & 0.03 & 2.3 \\
\hline 1687 & $\begin{array}{l}\text { Thioredoxin-dependent peroxide } \\
\text { reductase, mitochondrial }\end{array}$ & P30048 & PRDX3 & 7.7 & 78 & 27 & $4 / 22$ & 28 & 0.000005 & 9.3 \\
\hline 1840 & Caspase-3 & P42574 & CASP3 & 6.1 & 64 & 24 & $5 / 18$ & 32 & 0.0005 & 5.2 \\
\hline \multicolumn{11}{|c|}{ NCI-H28 cell proteome } \\
\hline 864 & Keratin, type II cytoskeletal 1 & P04264 & KRT1 & 8.1 & 78 & 22 & $7 / 41$ & 66 & 0.0005 & 2.1 \\
\hline 890 & $\begin{array}{l}\text { Serine/threonine-protein kinase PINK1, } \\
\text { mitochondrial, ISOFORM } 1\end{array}$ & Q9BXM7 & PINK1 & 9.4 & 102 & 52 & $26 / 54$ & 63 & 0.004 & 2.8 \\
\hline 940 & Heat shock factor protein 1 & Q00613 & HSF1 & 5.0 & 126 & 44 & $10 / 40$ & 57 & 0.000019 & 3.5 \\
\hline 970 & Keratin, type II cytoskeletal 1 & P04264 & KRT1 & 8.1 & 82 & 24 & $8 / 41$ & 66 & 0.00001 & 2.1 \\
\hline 1469 & Receptor of activated protein $\mathrm{C}$ kinase 1 & P63244 & RACK1 & 7.6 & 86 & 46 & $7 / 26$ & 35 & 0.0005 & 3.7 \\
\hline 1665 & L-lactate dehydrogenase $\mathrm{C}$ chain & P07864 & LDHC & 7.1 & 80 & 44 & $7 / 31$ & 36 & 0.000002 & 4.1 \\
\hline \multicolumn{11}{|c|}{ NCI-H2052 cell secretome } \\
\hline 512 & Sulfhydryl oxidase 1 & O00391 & QSOX1 & 9.1 & 82 & 32 & $8 / 36$ & 83 & 0.002 & 3.4 \\
\hline 1552 & L-lactate dehydrogenase A chain & P00338 & LDHA & 8.4 & 92 & 52 & $8 / 31$ & 37 & 0.03 & 2.4 \\
\hline 4083 & Prosaposin & $\mathrm{P} 07602$ & PSAP & 5.1 & 80 & 26 & $6 / 30$ & 58 & 0.02 & 7.4 \\
\hline
\end{tabular}

aProtein ID: SwissProt accession number. ${ }^{b}$ pI: isoelectric point. ${ }^{c}$ Mascot score after database search. ${ }^{\mathrm{d}}$ Cov\%: sequence coverage. ${ }^{\mathrm{e} P e p t}$ number of

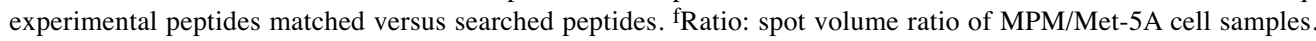

potential. Furthermore, quantitative proteomic studies have reported up-regulation of PSAP in gallbladder cancer and non-small cell lung carcinoma $(37,38)$. More importantly, PSAP has been also found over-expressed in several MPM cell line secretome by a previous proteomic analysis, which supports our finding (14). The next in line for expression level among NCI-H2052 secreted proteins was QSOX1. This enzyme oxidizes thiols during protein folding, reducing molecular oxygen to hydrogen peroxide. At the N-terminus, QSOX1 contains homology domains with sequence similarity to protein disulfide isomerase (PDI) followed by one functional and one non-functional thioredoxin (TRX) domain while yeast sulfhydryl oxidase (ERV1)/ALR catalytic domains which drive the catalytic function of the enzyme are near the C-terminus (39). Unlike other related enzymes, which are commonly found in the endoplasmic reticulum, QSOX1 is localized to the Golgi apparatus membrane (QSOX1-Long) or secreted (QSOX1-Short). QSOX1 is up-regulated in quiescent fibroblast cells and secreted into the extracellular environment, where it contributes to laminin incorporation into the extracellular matrix (ECM), but it is also involved in protecting cells against oxidative stress-induced apoptosis $(25,40)$. QSOX1 is up-regulated in several types of malignancies, especially breast and pancreatic adenocarcinoma where it stimulates tumor cell growth and invasiveness as suggested by studies on cell lines (39). The importance of this enzyme in contributing to the metastatic diffusion is highlighted by its role in the interplay between cancer cells and ECM and observations which indicate its high expression in breast cancer as a negative prognostic factor $(39,41)$. Whereas a circulating peptide from QSOX1-L has been proposed as blood-based biomarker of pancreatic adenocarcinoma a recent proteomic-based study of primary lung cancer cell secretome has proposed QSOX1 as a potential tissue and serum biomarker of this cancer type $(42,43)$. In addition, a proteomic analysis of MPM cell line secretome has reported increased expression of this enzyme in malignant cells compared to normal cells (14). The third up-regulated protein in NCI-H2052 secretome was lactate dehydrogenase A (LDHA), which forms homo- or hetero-tetramer with LDHB. The tetrameric LDH enzyme catalyzes the simultaneous inter-conversion of pyruvate to lactate and nicotinamide adenine dinucleotide (NAD)H to NAD. Enhanced LDHA expression has been reported in a variety of malignancies where it is considered a key player of the 


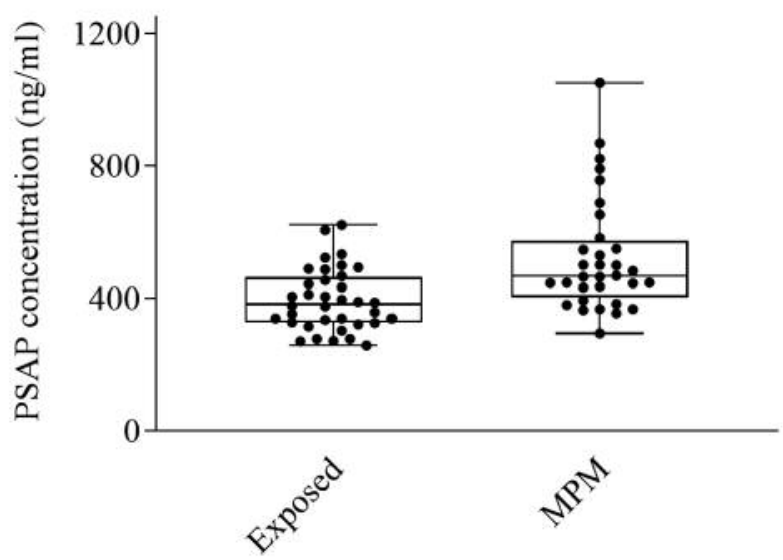

Figure 4. Box plot of PSAP serum concentrations. PSAP amount in each sample was determined using a commercially available sandwich-type ELISA kit, as described in Materials and Methods. Each data point represents mean of three independent experiments performed in duplicate. Statistical significance of the difference between groups was determined by the Mann-Whitney-Wilcoxon test. $* * * p<0.001$. Exposed: Asbestos-exposed healthy subjects; MPM: MPM patients.

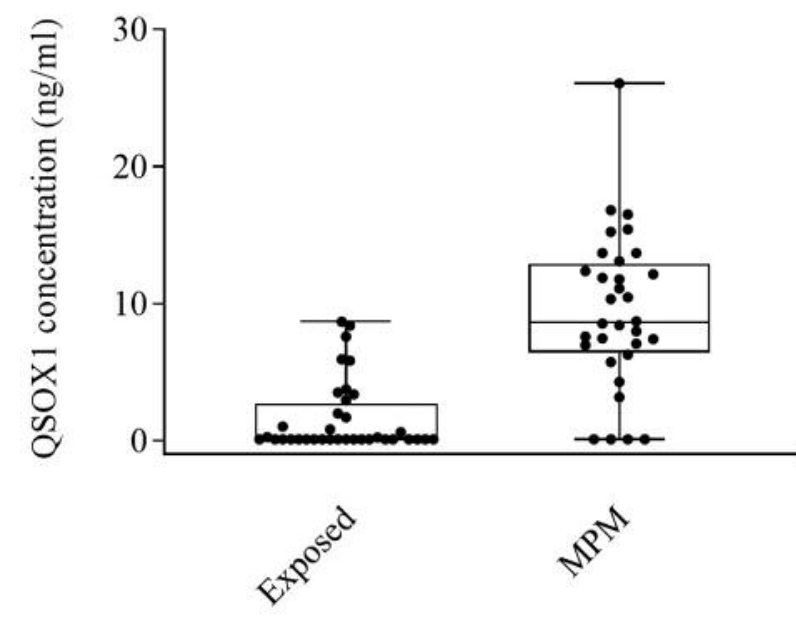

Figure 5. Box plot of QSOX1 serum concentrations. QSOX1 amount in each sample was determined using a commercially available sandwichtype ELISA kit, as described in Materials and Methods. Each data point represents mean of three independent experiments performed in duplicate. Statistical significance of the difference between groups was determined by the Mann-Whitney-Wilcoxon test. ***p<0.0001. Exposed: Asbestos-exposed healthy subjects; MPM: MPM patients.

Warburg effect (44). Indeed, the serum LDH concentration has been proposed as an inexpensive prognostic marker in solid tumors (45).

Our proteomic analysis of NCI-H2052 cell secretome revealed few up-regulated and down- regulated protein spots and thus just three over-expressed proteins were identified by
Table III. PSAP and QSOX1 serum concentrations.

\begin{tabular}{lcccc}
\hline & \multicolumn{2}{c}{ PSAP $(\mathrm{ng} / \mathrm{ml})$} & \multicolumn{2}{c}{ QSOX1 $(\mathrm{ng} / \mathrm{ml})$} \\
\cline { 2 - 5 } & Exposed $^{\mathrm{a}}$ & MPM $^{\mathrm{b}}$ & Exposed $^{\mathrm{a}}$ & MPM $^{\mathrm{b}}$ \\
\hline Median & 393.35 & 495.32 & 0.20 & 8.70 \\
$25^{\circ}$ percentile & 308.71 & 407.79 & 0.00 & 6.64 \\
$75^{\circ}$ percentile & 450.27 & 594.07 & 2.47 & 12.64 \\
$p$-Valuec $^{c}$ & \multicolumn{2}{c}{0.0002} & \multicolumn{2}{c}{$<0.0001$} \\
\hline
\end{tabular}

aExposed: Asbestos-exposed healthy subjects. bMPM: MPM patients. ${ }^{c} p$-Value of the difference between groups was determined by the MannWhitney-Wilcoxon test.

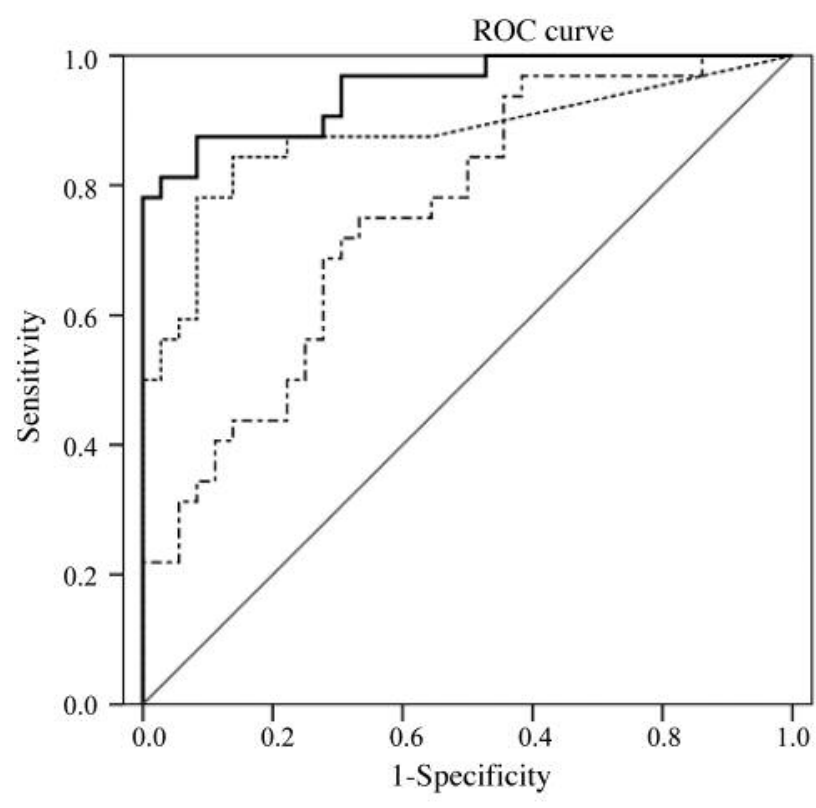

Source of the curve

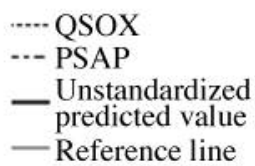

Figure 6. ROC curves of serum PSAP and QSOX1 concentrations. Individual and combined ROC curves in differentiating MPM patients $(n=32)$ from asbestos-exposed healthy subjects $(n=36)$ are shown. A logistic regression analysis was used to combine biomarker data.

MALDI-MS/MS. Of course, we can ascribe such discrepancy to the technical approach used by us which is less sensitive than the direct LC-MS/MS analysis of in solution digested proteins and iTRAQ ${ }^{\circledR}$ multiplex isobaric labelling technique $(13,14)$. Moreover, we used half the amount of CM proteins compared to Creaney et al. (14). Nevertheless, we identified 
two proteins out of three which have been also found in MPM cell secretome by Creaney et al. (14). Concerning NCIH28 secretome, which contained very low amounts of proteins, we feel to exclude cell reduced viability since all three cell lines showed similar viability as assessed by trypan blue exclusion. When secretome was tested for matrix metalloproteases (MMPs) by zymography, NCI-H28 cells did not show any while the NCI-H2052 cell secretome contained both MMP2 and MMP9 (data not shown). Indeed, the NCI$\mathrm{H} 28$ cell line, which is characterized by a homozygous deletion of the $\beta$-catenin gene, is quite unique among malignant cell lines since $\beta$-catenin acts as a growth suppressor while it is generally a positive-growth factor for most human cancers (46).

Since PSAP and QSOX1 are involved in protecting cells against oxidative stress that is a major player in malignant transformation they are indeed related to MPM biology and can be considered as potential drug targets and biomarkers (24-26). Thus, in the attempt to validate the proteomic results and predict a possible diagnostic value of the two secreted proteins, we measured PSAP and QSOX1 levels in MPM patient and asbestos-exposed subject (controls) sera using commercially available ELISA kits. In this way, significantly higher PSAP concentrations were found in MPM patient than asbestos-exposed healthy control sera $(p<0.001)$ thus suggesting a potential significance as a biomarker. However, an analysis of PSAP diagnostic power using the ROC curve did not yield very high specificity and sensitivity values. The AUC was comparable to that reported for ostepontin by Grigoriu et al. (47), which examined similar patient and control groups. PSAP has been also proposed as a potential prognostic tissue and serum biomarker in prostate cancer (48). Regarding QSOX1, the median serum concentration found in MPM patient sera was significantly higher $(p<0.0001)$ than in control healthy subject sera. The diagnostic power of QSOX1 appears to be better than that of PSAP as indicated by an AUC value of 0.85 versus 0.75 . The AUC for QSOX1 is comparable to that reported for SMRP by most studies on similar patient and control populations (5). The combination of both biomarkers shifted the AUC value to 0.95 suggesting the importance of using biomarker panels to improve their predictive value. Moreover, this AUC value is slightly higher than that reported by us for combinations of well established MPM biomarkers (29).

The strength of our work is the identification of two proteins, PSAP and QSOX1, related to cancer biology by proteomic analysis of MPM cell secretome, but more importantly their validation in MPM patient sera. The significantly higher protein concentration in MPM patients than asbestos-exposed healthy subjects highlights their significance as putative biomarkers. A further analysis has revealed their good diagnostic power but also pointed out the importance of using biomarker panels to improve the discriminative potency. Data presented also suggest that the combination of PSAP and QSOX1 can be considered as a biomarker panel for screening asbestos-exposed subjects. Of course, further studies on larger cohorts of patients and control subjects are needed to confirm our finding and also reveal a possible prognostic value of the novel biomarkers.

\section{Conflicts of Interest}

The Authors declare that they have no potential conflicts of interest.

\section{Authors' Contributions}

MRM, LG, AL: designed the study, coordinated the research, analyzed data and wrote the manuscript; RF: coordinated the study, performed the clinical evaluation of patients and control subjects and helped to draft the manuscript; AC, PF: performed the clinical evaluation of patients and control subjects; SL, FC, VDA: carried out cell culture, sample preparation and protein separation by electrophoresis; SL, FC, AB: carried out ELISA and statistical analysis; GG: carried out standard biochemical assays; VG, LP: carried out MALDI-TOF/TOF and analyzed MS data. All authors read and approved the final version of the manuscript.

\section{Acknowledgements}

This research was supported by grant from University of Pisa (PRA_2017_64) to RF. The funder had no role in study design, data collection and analysis, decision to publish, or preparation of the manuscript.

\section{References}

1 Zucali PA, Ceresoli GL, De Vincenzo F, Simonelli M, Lorenzi E, Gianoncelli L and Santoro A: Advances in the biology of malignant pleural mesothelioma. Cancer Treat Rev 37(7): 543558, 2011. PMID: 21288646. DOI: 10.1016/j.ctrv.2011.01.001

2 van Zandwijk N, Clarke C, Henderson D, Musk AW, Fong K, Nowak A, Loneragan R, McCaughan B, Boyer M, Feigen M, Currow D, Schofield P, Nick Pavlakis BI, McLean J, Marshall $\mathrm{H}$, Leong S, Keena V and Penman A: Guidelines for the diagnosis and treatment of malignant pleural mesothelioma. J Thorac Dis 5(6): E254-307, 2013. PMID: 24416529. DOI: 10.3978/j.issn.2072-1439.2013.11.28

3 Panou V, Vyberg M, Weinreich UM, Meristoudis C, Falkmer UG and Røe OD: The established and future biomarkers of malignant pleural mesothelioma. Cancer Treat Rev 41(6): 486495, 2015. PMID: 25979846. DOI: 10.1016/j.ctrv.2015.05.001

4 Sun HH, Vaynblat A and Pass HI: Diagnosis and prognosisreview of biomarkers for mesothelioma. Ann Transl Med 5(11): 244, 2017. PMID: 28706912. DOI: 10.21037/atm. 2017.06.60

5 Lagniau S, Lamote K, van Meerbeeck JP and Vermaelen KY: Biomarkers for early diagnosis of malignant mesothelioma: Do we need another moonshot? Oncotarget 8(32): 53751-53762, 2017. PMID: 28881848. DOI: 10.18632/oncotarget. 17910

6 Franceschini MC, Ferro P, Canessa PA, Battolla E, Dessanti P, Valentino A, Casolari L, Fontana V, Pezzi R, Fedeli F, Pistillo MP and Roncella S: Mesothelin in serum and pleural effusion in the diagnosis 
of malignant pleural mesothelioma with non-positive cytology. Anticancer Res 34(12): 7425-7429, 2014. PMID: 25503183.

7 Pass HI, Levin SM, Harbut MR, Melamed J, Chiriboga L, Donington J, Huflejt M, Carbone M, Chia D, Goodglick L, Goodman GE, Thornquist MD, Liu G, de Perrot M, Tsao MS and Goparaju C: Fibulin-3 as a blood and effusion biomarker for pleural mesothelioma. N Engl J Med 367(15): 1417-2147, 2012. PMID: 23050525. DOI: 10.1056/NEJMoa1115050

8 Creaney J, Dick IM, Meniawy TM, Leong SL, Leon JS, Demelker Y, Segal A, Musk AW, Lee YC, Skates SJ, Nowak AK and Robinson BW: Comparison of fibulin-3 and mesothelin as markers in malignant mesothelioma. Thorax 69(10): 895-902, 2014. PMID: 25037982. DOI: 10.1136/thoraxjnl-2014-205205

9 Battolla E, Canessa PA, Ferro P,Franceschini MC, Fontana V, Dessanti P, Pinelli V, Morabito A, Fedeli F, Pistillo MP and Roncella S: Comparison of the diagnostic performance of fibulin-3 and mesothelin in patients with pleural effusions from malignant mesothelioma. Anticancer Res 37(3): 1387-1391, 2017. PMID: 28314308.

10 Fontana V, Pistillo MP, Vigani A, Canessa PA, Berisso G, Giannoni U, Ferro P, Franceschini MC, Carosio R, Tonarelli M, Rossi C, Dessanti P and Roncella S: determination of mesothelin levels in pleural effusion does not help predict survival of patients with malignant pleural mesothelioma. Anticancer Res 39(9): 52195223, 2019. PMID: 31519636. DOI: 10.21873/anticanres.13719

11 Micolucci L, Akhtar MM, Olivieri F, Rippo MR and Procopio AD: Diagnostic value of microRNAs in asbestos exposure and malignant mesothelioma: systematic review and qualitative meta-analysis. Oncotarget 7(36): 58606-58637, 2016. PMID: 27259231. DOI: $10.18632 /$ oncotarget.9686

12 Greening DW, Ji H, Chen M, Robinson BW, Dick IM, Creaney $\mathrm{J}$ and Simpson RJ: Secreted primary human malignant mesothelioma exosome signature reflects oncogenic cargo. Sci Rep 6: 32643, 2016. PMID: 27605433. DOI: 10.1038/srep32643

13 Manfredi M, Martinotti S, Gosetti F, Ranzato E and Marengo E: The secretome signature of malignant mesothelioma cell lines. J Proteomics 145: 3-10, 2016. PMID: 26921831. DOI: 10.1016/j.jprot.2016.02.021

14 Creaney J, Dick IM, Leon JS and Robinson BW: A proteomic analysis of the malignant mesothelioma secretome using iTRAQ. Cancer Genomics Proteomics 14(2): 103-117, 2017. PMID: 28387650 .

15 Fazzini A, D’Antongiovanni V, Giusti L, Da Valle Y, Ciregia F, Piano I, Caputo A, D’Ursi AM, Gargini C, Lucacchini A and Mazzoni MR: Altered protease-activated receptor-1 expression and signaling in a malignant pleural mesothelioma cellì line, NCI-H28, with homozygous deletion of the $\beta$-catenin gene. PLoS One 9(11): e111550, 2014. PMID: 25364818. DOI: $10.1371 /$ journal.pone. 0111550

16 Kanaji N, Kita N, Kadowaki N and Bandoh S: fibronectin and hepatocyte growth factor produced by lung fibroblasts augment migration and invasion of malignant pleural mesothelioma cells. Anticancer Res 37(5): 2393-2400, 2017. PMID: 28476806. DOI: 10.21873/anticanres.11578

17 Ciregia F, Giusti L, Da Valle Y, Donadio E, Consensi A, Giacomelli C, SernissiF, Scarpellini P, Maggi F, Lucacchini A and Bazzichi L: A multidisciplinary approach to study a couple of monozygotic twins discordant for the chronic fatigue syndrome: a focus on potential salivary biomarkers. J Transl Med 11: 243, 2013. PMID: 24088505. DOI: 10.1186/1479-5876-11-243
18 Giusti L, Baldini C, Bazzichi L, Ciregia F, Tonazzini I, Mascia G, Giannaccini G, Bombardieri S and Lucacchini A: Proteome analysis of whole saliva: a new tool for rheumatic diseases - the example of Sjögren's syndrome. Proteomics 7(16): 1634-1643, 2007. PMID: 17436266 . DOI: 10.1002/pmic.200600783

19 Giusti L, Iacconi P, Da Valle Y, Ciregia F, Ventroni T, Donadio E, Giannaccini G, Chiarugi M, Torregrossa L, Proietti A, Basolo $\mathrm{F}$ and Lucacchini A: A proteomic profile of washing fluid from the colorectal tract to search for potential biomarkers of colon cancer. Mol Biosyst 8(4): 1088-1099, 2012. PMID: 22294321. DOI: $10.1039 / \mathrm{c} 2 \mathrm{mb} 05394 \mathrm{~b}$

20 Aude-Garcia C, Collin-Faure V, Luche S and Rabilloud T: Improvements and simplifications in in-gel fluorescent detection of proteins using ruthenium II tris-(bathophenanthroline disulfonate): the poor man's fluorescent detection method. Proteomics 11(2): 324-328, 2011. PMID: 21204259. DOI: 10.1002/pmic. 201000370

21 Giusti L, Angeloni C, Barbalace MC, Lacerenza S, Ciregia F, Ronci M, Urbani A, Manera C, Digiacomo M, Macchia M, Mazzoni MR, Lucacchini A and Hrelia SA: Proteomic approach to uncover neuroprotective mechanisms of oleocanthal against oxidative stress. Int J Mol Sci 19(8): 2329, 2018. PMID: 30096819. DOI: $10.3390 /$ ijms 19082329

22 Soggiu A, Piras C, Greco V, Devoto P, Urbani A, Calzetta L, Bortolato $\mathrm{M}$ and Roncada P: Exploring the neural mechanisms of finasteride: a proteomic analysis in the nucleus accumbens. Psychoneuroendocrinology 74: 387-396, 2016. PMID: 27750143. DOI: $10.1016 /$ j.psyneuen.2016.10.001

23 Piras C, Soggiu A, Greco V, Martino PA, Del Chierico F, Putignani L, Urbani A, Nally JE, Bonizzi L and Roncada P: Mechanisms of antibiotic resistance to enrofloxacin in uropathogenic Escherichia coli in dog. J Proteomics 127(pt8): 365-376, 2015. PMID: 26066767. DOI: $10.1016 /$ j.jprot.2015.05.040

24 Ochiai T, Takenaka Y, Kuramoto Y, Kasuya M, Fukuda K, Kimura M, Shimeno H, Misasi R, Hiraiwa M and Soeda S: Molecular mechanism for neuro-protective effect of prosaposin against oxidative stress: its regulation of dimeric transcription factor formation. Biochim Biophys Acta 1780(12): 1441-1447, 2008. PMID: 18706485. DOI: 10.1016/j.bbagen.2008.07.010

25 Morel C, Adami P, Musard JF, Duval D, Radom J and Jouvenot M: Involvement of sulfhydryl oxidase QSOX1 in the protection of cells against oxidative stress-induced apoptosis. Exp Cell Res 313(19): 3971-3982, 2007. PMID: 17927979. DOI: 10.1016/ j.yexcr.2007.09.003

26 Kudryavtseva AV, Krasnov GS, Dmitriev AA, Alekseev BY, Kardymon OL, Sadritdinova AF, Fedorova MS, Pokrovsky AV, Melnikova NV, Kaprin AD, Moskalev AA and Snezhkina AV: Mitochondrial dysfunction and oxidative stress in aging and cancer. Oncotarget 7(29): 44879-44905, 2016. PMID: 27270647. DOI: $10.18632 /$ oncotarget.9821

27 Benedetti S, Nuvoli B, Catalani S and Galati R: Reactive oxygen species a double-edged sword for mesothelioma. Oncotarget 6(18): 16848-16865, 2015. PMID: 26078352. DOI: 10.18632/ oncotarget 4253

28 Arnold DT and Maskell NA: Biomarkers in mesothelioma. Ann Clin Biochem 55(1): 49-58, 2018. PMID: 29058958. DOI: $10.1177 / 0004563217741145$

29 Bonotti A, Foddis R, Landi S, Melaiu O, De Santi C, Giusti L, Donadio E,Ciregia F, Mazzoni MR, Lucacchini A, Bovenzi M, Comar M, Pantani E, Pistelli A and Cristaudo A: A novel panel 
of serum biomarkers for MPM diagnosis. Dis Markers 2017: 3510984, 2017. PMID: 28348450. DOI: 10.1155/2017/3510984

30 Meyer RC, Giddens MM, Coleman BM and Hall RA: The protective role of prosaposin and its receptors in the nervous system. Brain Res 1585: 1-12, 2014. PMID: 25130661. DOI: 10.1016/j.brainres.2014.08.022

31 O'Brien JS, Carson GS, Seo HC, Hiraiwa M and KishimotoY: Identification of prosaposin as a neurotrophic factor. Proc Natl Acad Sci USA 91(20): 9593-9596, 1994. PMID: 7937812. DOI: 10.1073/pnas.91.20.9593

32 Koochekpour S, Sartor O, Lee TJ, Zieske A, Patten DY, Hiraiwa M, Sandhoff K, Remmel N and Minokadeh A: Prosaptide TX14A stimulates growth, migration, and invasion and activates the Raf-MEK-ERK-RSK-Elk-1 signaling pathway in prostate cancer cells. Prostate 61(2): 114-123, 2004. PMID: 15305334. DOI: $10.1002 /$ pros.20082

33 Koochekpour S, Zhuang YJ, Beroukhim R, Hsieh CL, Hofer MD, Zhau HE, Hiraiwa M, Pattan DY, Ware JL, Luftig RB, Sandhoff K, Sawyers CL, Pienta KJ, Rubin MA, Vessella RL, Sellers WR and Sartor O: Amplification and overexpression of prosaposin in prostate cancer. Genes Chromosomes Cancer 44(4): 351-364, 2005. PMID: 16080200. DOI: 10.1002/ gcc. 20249

34 Koochekpour S, Lee TJ, Wang R, Culig Z, Delorme N, Caffey $S$, Marrero L and Aguirre J: Prosaposin upregulates AR and PSA expression and activity in prostate cancer cells (LNCaP). Prostate 67(2): 178-189, 2007. PMID: 17044040. DOI: $10.1002 /$ pros. 20513

35 Hu S, Delorme N, Liu Z, Liu T, Velasco-Gonzalez C, Garai J, Pullikuth A and Koochekpour S: Prosaposin down-modulation decreases metastatic prostate cancer cell adhesion, migration, and invasion. Mol Cancer 9: 30, 2010. PMID: 20132547. DOI: 10.1186/1476-4598-9-30

36 Kang SY, Halvorsen OJ, Gravdal K, Bhattacharya N, Lee JM, Liu NW, Johnston BT, Johnston AB, Haukaas SA, Aamodt K, Yoo S, Akslen LA and Watnick RS: Prosaposin inhibits tumor metastasis via paracrine and endocrine stimulation of stromal p53 and Tsp-1. Proc Natl Acad Sci USA 106(29): 12115-12120, 2009. PMID: 19581582. DOI: 10.1073/pnas.0903120106

37 Sahasrabuddhe NA, Barbhuiya MA, Bhunia S, Subbannayya T, Gowda H, Advani J, Shrivastav BR, Navani S, Leal P, Roa JC, Chaerkady R, Gupta S, Chatterjee A, Pandey A and Tiwari PK: Identification of prosaposin and transgelin as potential biomarkers for gallbladder cancer using quantitative proteomics. Biochem Biophys Res Commun 446(4): 863-869, 2014. PMID: 24657443. DOI: 10.1016/j.bbrc.2014.03.017

38 Yang S, Chen L, Chan DW, Li QK and Zhang H: Protein signatures of molecular pathways in non-small cell lung carcinoma (NSCLC): comparison of glycoproteomics and global proteomics. Clin Proteomics 14: 31, 2017. PMID: 28814946. DOI: $10.1186 / \mathrm{s} 12014-017-9166-9$

39 Lake DF and Faigel DO: The emerging role of QSOX1 in cancer. Antioxid Redox Signal 21(3): 485-496, 2014. PMID: 24359107. DOI: 10.1089 /ars.2013.5572
40 Ilani T, Alon A, Grossman I, Horowitz B, Kartvelishvily E, Cohen SR and Fass D: A secreted disulfide catalyst controls extracellular matrix composition and function. Science 341(6141): 74-76, 2013. PMID: 23704371. DOI: 10.1126/science.1238279

41 Knutsvik G, Collett K, Arnes J, Akslen LA and Stefansson IM: QSOX1 expression is associated with aggressive tumor features and reduced survival in breast carcinomas. Mod Pathol 29(12): 14851491, 2016. PMID: 27562495. DOI: 10.1038/modpathol.2016.148

42 Antwi K, Hostetter G, Demeure MJ, Katchman BA, Decker GA, Ruiz Y, Sielaff TD, Koep LJ and Lake DF: Analysis of the plasma peptidome from pancreas cancer patients connects a peptide in plasma to overexpression of the parent protein in tumors. J Proteome Res 8(10): 4722-4731, 2009. PMID: 19795908. DOI: $10.1021 /$ pr900414f

43 Sung HJ, Ahn JM, Yoon YH, Na SS, Choi YJ, Kim YI, Lee SY, Lee EB, Cho S and Cho JY: Quiescin sulfhydryl oxidase 1 (QSOX1) secreted by lung cancer cells promotes cancer metastasis. Int J Mol Sci 19(10): E3213, 2018. PMID: 30336636. DOI: 10.3390/ijms 19103213

44 Valvona CJ, Fillmore HL, Nunn PB and Pilkington GJ: The regulation and function of lactate dehydrogenase $\mathrm{A}$ : therapeutic potential in brain tumor. Brain Pathol 26(1): 3-17, 2016. PMID: 26269128. DOI: 10.1111/bpa.12299

45 Petrelli F, Cabiddu M, Coinu A, Borgonovo K, Ghilardi M, Lonati V and Barni S: Prognostic role of lactate dehydrogenase in solid tumors: a systematic review and meta-analysis of 76 studies. Acta Oncol 54(7): 961-970, 2015. PMID: 25984930. DOI: $10.3109 / 0284186 X .2015 .1043026$

46 Usami N, Sekido Y, Maeda O, Yamamoto K, Minna JD, Hasegawa Y, Yoshioka H, Imaizumi M, Ueda Y, Takahashi M and Shimokata K: Beta-catenin inhibits cell growth of a malignant mesothelioma cell line, NCI-H28, with a 3p21.3 homozygous deletion. Oncogene 22(39): 7923-7930, 2003. PMID: 12970740. DOI: 10.1038/sj.onc.1206533

47 Grigoriu BD, Scherpereel A, Devos P, Chahine B, Letourneux M, Lebailly P, Grégoire M, Porte H, Copin MC and Lassalle P: Utility of osteopontin and serum mesothelin in malignant pleural mesothelioma diagnosis and prognosis assessment. Clin Cancer Res 13(10): 2928-2935, 2007. PMID: 17504993. DOI: 10.1158/1078-0432.CCR-06-2144

48 Koochekpour S, Hu S, Vellasco-Gonzalez C, Bernardo R, Azabdaftari G, Zhu G, Zhau HE, Chung LW and Vessella RL: Serum prosaposin levels are increased in patients with advanced prostate cancer. Prostate 72(3): 253-269, 2012. PMID: 21630292. DOI: $10.1002 / \operatorname{pros} .21427$ 